\title{
Study on Total Factor Productivity of Chinese Tea Industry and Regional Disparity based on DEA-Malmquist Model
}

\author{
ZHENG SUFANG \\ School of Internet Economics and Business \\ Fujian University of Technology \\ 999 Dongsanhuan Road, Gushan Town Jian Disctrict, Fuzhou, Fujian \\ CHINA
}

\begin{abstract}
The primary purpose of this study was to estimate and decompose Total Factor Productivity of tea industry in China to explore the resource of technical efficiency. The data was collected from the major 18 tea producing provinces in China 2015-2019. The data envelopment analysis (DEA) program and DEAMalmquist index was used to estimate the efficiency scores. Results revealed that TFP has been increasing and there are great differences in TFP among different provinces. The major reason for improvement of TFP was the increasing technological change and technical efficiency was influenced by pure technical efficiency and scale efficiency. The findings suggest that the elderly and better educated farmers combined their previous knowledge of farming adopting proper farming practices may achieve production efficiency.
\end{abstract}

Key-Words:- DEA; Malmquist; Total Factor Productivity; Technical Efficiency

Received: February 21, 2020. Revised: July 16, 2020. Accepted: July 21, 2020. Published: July 28, 2020.

\section{Introduction}

Tea is a traditional and advantageous industry in China. China is a major tea producer and the world's largest tea exporter. By the end of 2018, the cultivated area was 2.99 million hectares, the total production was 2.61 million tons. The total export was 365,000 tons and amount of export was 1.8 billion dollars. Chinese tea was exported to all the five continents, among which China export the most amount to Africa, accounting for $46.3 \%$ of the total amount. the export of Chinese tea covers 100 countries and areas in the world, which reveals the concentration of the export market.

But in recent years there were some prominent problems existing in the tea industry. Firstly, the tea plantation area grew too quickly which increased the potential risks. Tea production continued to grow, but the consumption growth impetus was insufficient. Under the circumstance of slow market demand and low sale price, the disparities between supply and demand will be deepened and the industry will be risky. Secondly, the production costs were continuously increased and profit margin was reduced. Due to the rising price in agricultural materials and labour, the production costs of tea have greatly risen. The shortage of workers seriously restricted the development of tea industry. The low market sale price reduced the profit margin in tea production, processing, wholesale and retail.

Thirdly, the mechanization degree of tea production needs to be promptly improved. There was some progress in the promotion of tea plantation and picking machinery and tea processing machinery, but some technique was not mature and practical enough to promote. Tea industry is a typical labour-intensive industry, but shortage of workers and high salary low efficiency restricted the productivity effect and it was urgent to realize the mechanization, intelligence and practicality.

Finally, tea industry as the third industry has not formed an important driving force which restricted the overall benefits of the industry. The major reason was the insufficient attention to the tea culture. Nowadays, China's tea culture tourism market is still at primary stage. There was great improvement in tea products development, tourism route design, tour time and consumption.

Hence, it has a significant contribution to increasing Chinese foreign exchange earnings to improve the Total Factor Productivity of Chinese tea then to increase the exporting incomes. But what's the source of the rapid growth of China's tea industry? Was it dependent on massive factors input or technical progress or the improvement of technical 
efficiency? Was China's tea industry sustainable? The specific aims of the study are to examine these problems to promote the future development of tea industry and formulation of tea industry production policy.

\section{Literature Review}

Data Envelopment Analysis, parametric regression method and stochastic frontier approach was an important area in economic research and was applied in agricultural economy. The study outside China was relatively early and mature. took rice planting farmers in Jiangsu Province of China as example to estimate the technical progress and allocative efficiency of Chinese agriculture. Growth of agriculture TFP in Zhejiang Province of China was studied by using multi-input and output distance function method and found out that the main reason for the growth of TFP was the improvement of technical progress and efficiency. All these studies illustrated the agricultural technical efficiency from at the macro level and laid the foundation for relative research. Van Ho et al. applied propensity score matching to control self-selection, in assessing profit efficiency of safe and conventional tea farming. The results of this study indicate that, the average profit efficiency of tea farmers was around 74 percent, suggesting 26 percent of profit was lost due to inefficient use of inputs.[1] Hong and Yabi, conducted a research on enhancement of efficiency perspective of tea production in Vietnam. The results showed that, the appropriate use of technology (sound input application) may increase average production of tea leaves by 10.4 percent. The technical efficiency of the inputs, surveyed from the farms, on average varied in the range of 62.1 to 97 percent.[2]

Although the relative research on DEA in China was later than other countries but developed very quickly, many literatures were about it. The DEA-Malmquist index method can handle panel data to do dynamic evaluation. As a result, a large number of works have chosen the DEA-Malmquist index method to measure, such as Shuiping Zhang [3], Ke Li et al.,[4], and Decai Tang et al. [5].

Meng calculated the technical efficiency of Chinese agricultural operation by using non-parametric DEA efficiency evaluation method[6]. Fexter studied technical efficiency of smallholder tea production in South-Eastern Malawi[7]. Z. Ghaderi conducted efficiency analysis of traditional tea farms in Iran [8].
All above research results provided important foundation and references for subsequent studies.

Total Factor Productivity (TFP) represents the parts except factor inputs and it is an index to measure total output productivity for total input per unit. The parts which output productivity surpasses factor input growth are called the growth of TFP. By studying the growth of TFP, we can explore the source for output growth and identify the quality of output growth as well. The change of TFP can be divided into technical progress, technical efficiency, allocative efficiency and economic efficiency of scale[9]. There are also many literatures about the TFP , technical efficiency and technical efficiency amd their deterninants[10], technical efficiency and agriculture policy[11]. Besides, chemical components and pesticide have been widely used by tea farmers for protecting tea farms. Improper use of pesticides and chemical fertilizers has led to detrimental consequences for human health and the environment[12]. Reports on the production efficiency, advantages, and challenges of VietGAP tea production have appeared only in brief articles provided by the government or daily news agencies [13][14]. Hong and Yabe investigated the profit efficiency of conventional tea farmers[15][16]. Hence this study will use DEAMalquist index to calculate the TFP of tea industry in China and output elasticity of labor and capital. Meanwhile, the main source of TFP growth of Chinese tea industry was analyzed. The analysis results of this study have certain guiding significance to correctly understand the development of tea industry.

As for the technical efficiency in tea industry development, recent researches had reached some significant conclusion. But most existing studies only focused on the technical progress of tea industry, scale efficiency and technical efficiency was seldom deeply analyzed. The major study object was the whole tea industry and lack of in-depth analysis on the technical efficiency of different kinds of tea. Furthermore, some empirical research conclusion was against the actual facts. For example, the minus growth of technology in tea industry was not inconformity with the invention and usage of massive new technology in reality.

\section{Data and Methodology}

\subsection{DEA method}


Technical Efficiency (TE) is be defined as the ability of a firm to maximize output from a given set of inputs. Allocative efficiency is the ability of a firm to use inputs in optimal proportions, resulting into maximum profit at minimum cost.

The DEA is an analytical technique used for performance evaluation. It is a multifactor productivity exploration model used for assessing relative efficiencies of a homogenous set of decision making units (DMUS). The present study uses two main DEA models: CCR (Charnes-Cooper-Rhodes) and BCC (Baker-Charnes-Cooper). The CCR model is based on the assumption of constant return to scale (CRS) of the economic activities. The BCC model is based on the assumption of variable return to scale (VRS) of these activities. Assuming there are N DMUS, each of which uses $\mathrm{K}$ inputs and $\mathrm{M}$ outputs, then the relative efficiency score, is obtained by solving the following model. CRS as (linear) mathematical programming, (nonparametric) model, was proposed by Charnes et al, which uses a "ratioform" that defines "relative efficiency" as "ratio output to inputs"[17].

Model 1 CRS model

$\operatorname{Min} \theta_{\mathrm{c}}$

s.t. $\left\{\begin{array}{l}\theta_{c} x_{0}-\sum_{j=1}^{N} \lambda_{j} x_{j} \geq 0 \\ -y_{0}+\sum_{j=1}^{N} \lambda_{j} y_{j} \geq 0 \\ \lambda_{\mathrm{j}} \geq 0 \\ \mathrm{j}=1, \quad 2, \quad \ldots . \mathrm{N} \\ \theta_{\mathrm{c}} \geq 0\end{array}\right.$

Respectively, $\mathrm{x}_{0}$ and $\mathrm{y}_{0}$ represents for the input and output vector for tea production. $\mathrm{x}_{\mathrm{j}}$ and $\mathrm{y}_{\mathrm{j}}$ represents for $j$ th input and output vector of tea production. $\lambda_{j}$ represents for weight of every DMU, $\theta_{c}$ represents for the overall efficiency under the assumption of fixed returns of scale, the value is between 0 and 1 , which reflects the extent of input-output efficiency of tea production. If $\theta \mathrm{c}=1$, it shows that the input-output is completely effective. That is, both technical and scale efficiency is effective. The technical efficiency means that tea producers fully make use of resources to achieve maximum output and the best operational conditions. The scale efficiency means that tea production is on the stage of fixed returns of scale, i.e., the output expands or reduces as the same ratio with input. If $\theta_{\mathrm{c}}<1$, it means that the existing technical usage and the configuration of production factor is not on the best condition.

Model 2 VRS model

$\operatorname{Min} \theta_{\mathrm{v}}$

s.t. $\left\{\begin{array}{l}\theta_{\nu} x_{0}-\sum_{j=1}^{N} \lambda_{j} x_{j} \geq 0 \\ -y_{0}+\sum_{j=1}^{N} \lambda_{j} y_{j} \geq 0 \\ \lambda_{j} \geq 0 \\ j=1, \quad 2, \quad \ldots . . N\end{array}\right.$

$\theta_{v}$ stands for the pure technical efficiency. It can calculate what extent the pure technical efficiency caused the overall inefficiency under the guiding of input in tea production. The value of $\theta_{\mathrm{v}}$ is from 0 to 1 , the meaning of other variables is the same as CRS model.

The relation between the overall efficiency $\theta_{\mathrm{c}}$ under the condition of fixed returns of scale, the scale efficiency $\theta_{\mathrm{y}}$ under the condition of variable returns of scale and scale efficiency $\theta_{\mathrm{s}}$ is as follows:

$\theta_{\mathrm{c}}=\theta_{\mathrm{v}} \times \theta_{\mathrm{s}}, \quad \theta_{\mathrm{s}}=\theta_{\mathrm{d}} \theta_{\mathrm{v}}$

By examining the conversion relation between overall efficiency, pure technical efficiency and scale efficiency, the scale efficiency of every DMU can be further measured. It can estimate whether the scale of tea production is optimal under the condition of fixed input.

\subsection{DEA-Malmquist index model}

In 1953, Malmquist put forward the Malmquist index for the first time, and then Caves and others used the Malmquist index to measure productivity. Fare and others further put forward that a distance function was used to describe production technology of multiple input variables and multiple output variables[18]. Using the directional output method or directional input method to define the distance function and giving the input variable matrix, an output distance function is defined as the optimal 
proportion of output variable matrix. According to the Malmquist index based on DEA built by Fare and others, this article uses directional output method to measure green total factor productivity of the food industry. Distance function of output variables is defined as follows:

$\mathrm{D}_{0}(\mathrm{x}, \mathrm{y})=\inf \{\delta:(\mathrm{x}, \mathrm{y} / \delta) \in \rho(\mathrm{x})\}(1)$

In Eq. 1, $\mathrm{x}$ and $\mathrm{y}$ represent input variable and input matrix, $d$ represents the directional output efficiency indicator of Farrell, and $\rho(x)$ represents possible produce collection. If $\mathrm{y}$ is in $\mathrm{p}(\mathrm{x})$ 's internal, function value will be less than or equal to 1 ; if $y$ is on $\rho(x)$ 's external boundary, function value will be equal to 1 ; if $y$ is in $\rho(x)$ 's outside, function value will be more than 1. In the period of $t$ to $(t+1)$, a Malmquist index that measures total factor productivity can be represented as

$$
\begin{aligned}
& \operatorname{MI}_{0}\left(x_{t+1}, y_{t+1}, x_{t}, y_{t}\right) \\
& =\left[\frac{D_{0}^{t}\left(x_{t+1}, y_{t+1}\right)}{D_{0}^{t}\left(x_{t}, y_{t}\right)} \times \frac{D_{0}^{t+1}\left(x_{t+1}, y_{t+1}\right)}{D_{0}^{t+1}\left(x_{t}, y_{t}\right)}\right]^{\frac{1}{2}}
\end{aligned}
$$

In Eq. 2, $\left(\mathrm{x}_{\mathrm{t}+1}, \mathrm{y}_{\mathrm{t}+1}\right)$ and $\left(\mathrm{x}_{\mathrm{t}}, \mathrm{y}_{\mathrm{t}}\right)$ indicate input and output vector of period $(t+1)$, respectively, and period $t ; D t^{0}$ and $D_{0}{ }^{t+1}$ indicate distance function of period $t$ and period $(t+1)$ reference on period $t$ technology $T$ ${ }^{t+1}$, respectively. According to Fare's research, under the assumption of constant returns to scale, the Malmquist index can be further decomposed into the product of EC and TC. When EC $>1$, decision making units approach a frontier, which means that efficiency rises and efficiency declines. When $\mathrm{TC}>1$, the production possibilities frontier is out-shift, which means that efficiency rises and efficiency declines. EC can also be further decomposed into the product of PEC and SEC. Using linear programming to calculate various kinds of distance functions of input and output gets the Malmquist productivity index[19].

\subsection{Data and variables}

This empirical study on the measurement of efficiency, both technical and scale, is entirely based on secondary data. The panel data source is China Statistical Yearbook 2015-2019 and China Rural Statistical Yearbook 2015-2019, published annually by State Statistics Bureau in China.

I have chosen 18 major tea-producing provinces in China. They are Jiangsu, Zhejiang, Anhui, Fujian, Jiangxi, Shandong, Henan, Hubei, Hunan,
Guangdong, Guangxi, Hainan, Chongqing, Sichuan, Guizhou, Yunnan, Shaanxi and Gansu. Because of lack of data in Tibet, it was eliminated to reduce the influence on the estimation results.

The input indicator of TFP is mainly manifested in the aspects such as Agricultural Fixed Assets, Total Agricultural Machinery Power, Employees at the end of the year, fertilizer and pesticide use.

Labor Input: Labor input generally refers to the labor amount of actual investment in the production process. Labor input can be measured by labor time of standard labor intensity. Because market mechanisms and the income distributionm system are imperfect in China, statistical data is lacking. Thus, this article uses "employees at the end of the year (people)" to measure.

Capital Input: Barro et al. considered that capital input could be measured by service flow of physical capital in theory. But there is no such measure indicator in reality, and a large number of scholars select net value of fixed assets or liquid assets to measure capital input when measuring total factor productivity. Therefore, this article uses "agricultural fixed assets) to measure.

Fertilizer and Pesticide use: It means the other materials input in tea production. Fertilizer and pesticide were necessary to tea cultivation and planting. So this input should be considered into the estimation of TFP[4].

When selecting TFP output indicators, we generally choose industrial added value or industrial gross output value. But as a result of the change of calculation methods of industrial added value, China has no longer released the data of industrial gross output value since 2012. In order to maintain the continuity of data, this paper chose the yield and output value of tea industry.

Natural endowments are important to the tea production, but production technology is very critical to the whole production. As for tea production, the five inputs are difficult to gather and the existing yearbooks have not listed the needed data. Hence the author used the agricultural data to replace them.

\section{Empirical Analysis Results}

This study uses the BCC model of input-oriented and uses DEAP2.1 software to estimate the technical 
efficiency of China's tea industry. The results are shown in Figure 1.

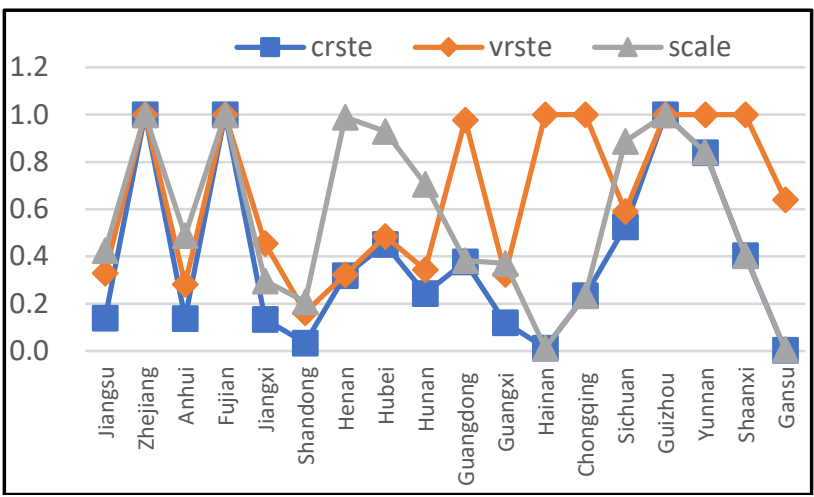

Crste=technical efficiency from CRS DEA; Vrste=technical efficiency from VRS DEA; Scale $=$ scale efficienc $y=$ crste $/$ vrste

Figure 1 Technical efficiency of tea industry in 18 Chinese provinces under input-oriented DEA BCC model

The estimated results of technical efficiency in different provinces were shown in Figure 1, there are great regional disparities. Zhejiang, Fujian and Guizhou had effective technical efficiency which was 1. It illustrated that these three provinces had the optimal technical efficiency. Hainan, Chongqing, Yunnan and Shaanxi had effective pure technical efficiency, which meant that these four provinces had higher output capability given input resources. Meanwhile Zhejiang, Fujian and Guizhou had effective scale efficiency, which represented their optimal scale. There were 13 provinces had increasing return of scale, accounting for $72 \%, 2$ provinces had decreasing return of scale, accounting for $11 \%$ and 3 provinces had constant return of scale, accounting for $17 \%$. It manifested that most tea producing provinces could expand tea production scale appropriately.

The author used DEA-Malmquist index to estimate Total Factor Productivity, Technological Change, Technical Efficiency Change. DEAP2.1 software was used and results are as follow:

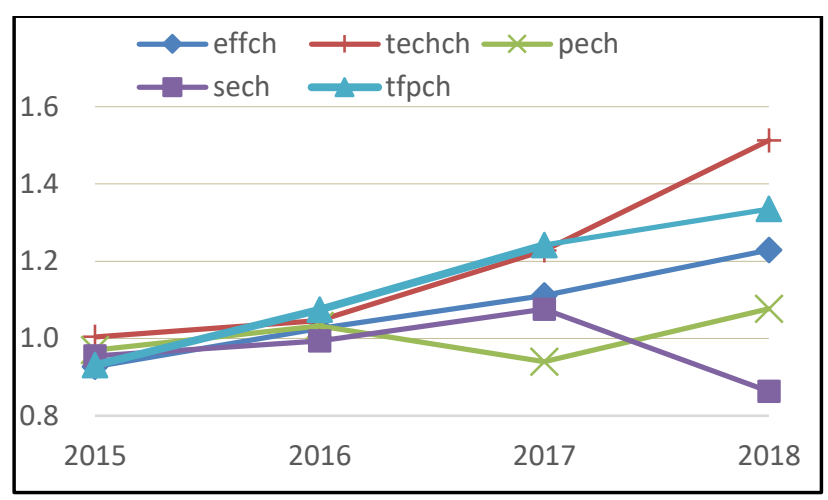

Figure 2 The tea industry total factor productivity Malmquist index and its decomposition from 2014 to 2018. Note: EFFCH: TECHNICAL EFFICIENCY CHANGE; TECHCH TECHNOLOGICAL CHANGE; PECH: PURE TECHNICAL EFFICIENCY CHANGE; SECH: SCALE EFFICIENCY CHANGE; FPCH: TOTAL FACTOR PRODUCTIVITY CHANGE

As shown in Figure 2, TFP Malmquist index of China's tea industry showed a trend of fluctuant rise from 2015 to 2018. During the period of 2016-2018, the TFP Malmquist index was more than 1. It illustrates that TFP Malmquist index of tea industry had an improving trend in general. Only during the period of 2014-2015 was the Malmquist index less than 1 , which meant the index fell during this period.

The technical efficiency change index can be further decomposed into pure technical efficiency change index and scale efficiency change index. We further analysed the reason for technical efficiency change from these two aspects. During the period of 20142018, pure technical efficiency had remained in a rising trend. The pure technical efficiency measures the output capability under given input resources. In addition to the period of 2014-2017, scale efficiency had kept rising, which meant the whole tea industry was in a state of scale effectiveness. Therefore the major reason for technical efficiency falling is scale efficiency falling during 20117-2018. Overall TFP of China's tea industry increased by $12.8 \%$ on average; and technical efficiency increased by $9.7 \%$ on average and technology progress level increased by $14.9 \%$ on average. The major reason for TFP of China's tea industry increasing is technology progress and technical efficiency increase.

Table 1 TFP and Five Indices in 18 Chinese main teaproducing provinces

\begin{tabular}{|l|r|r|r|r|c|}
\hline PROVINCE & EFFCH & TECHCH & PECH & SECH & TFPCH \\
\hline Jiangsu & 0.651 & 1.385 & 0.679 & 0.958 & 0.902 \\
\hline Zhejiang & 1.000 & 1.105 & 1.000 & 1.000 & 1.105 \\
\hline
\end{tabular}




\begin{tabular}{|c|c|c|c|c|c|}
\hline Anhui & 0.981 & 1.342 & 0.974 & 1.008 & 1.317 \\
\hline Fujian & 1.000 & 1.442 & 1.000 & 1.000 & 1.442 \\
\hline Jiangxi & 1.055 & 1.306 & 1.053 & 1.002 & 1.378 \\
\hline Shandong & 1.039 & 1.197 & 1.033 & 1.006 & 1.243 \\
\hline Henan & 0.956 & 1.387 & 0.986 & 0.970 & 1.326 \\
\hline Hubei & 1.016 & 1.378 & 1.040 & 0.977 & 1.400 \\
\hline Hunan & 0.928 & 1.344 & 0.938 & 0.990 & 1.248 \\
\hline Guangdong & 1.305 & 1.494 & 1.470 & 0.888 & 1.950 \\
\hline Guangxi & 0.968 & 1.246 & 1.006 & 0.963 & 1.207 \\
\hline Hainan & 1.014 & 1.283 & 1.000 & 1.014 & 1.301 \\
\hline Chongqing & 0.968 & 1.501 & 1.000 & 0.968 & 1.453 \\
\hline Sichuan & 0.980 & 1.293 & 1.034 & 0.948 & 1.267 \\
\hline Guizhou & 1.000 & 1.432 & 1.000 & 1.000 & 1.432 \\
\hline Yunnan & 0.994 & 1.315 & 1.026 & 0.968 & 1.307 \\
\hline Shaanxi & 0.858 & 1.388 & 1.000 & 0.858 & 1.191 \\
\hline Gansu & 0.922 & 1.390 & 0.982 & 0.939 & 1.282 \\
\hline Mean & 0.972 & 1.342 & 1.004 & 0.969 & 1.305 \\
\hline
\end{tabular}

EFFCH: TECHNICAL EFFICIENCY CHANGE; TECHCH: TECHNOLOGICAL CHANGE; PECH: PURE TECHNICAL EFFICIENCY CHANGE; SECH: SCALE EFFICIENCY CHANGE; TFPCH: TOTAL FACTOR PRODUCTIVITY CHANGE

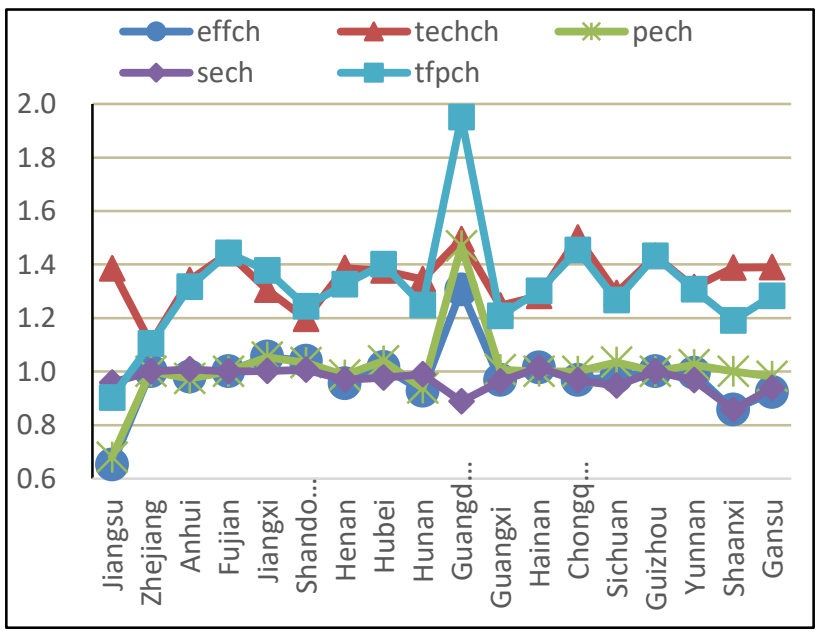

Figure 3 TFP and Five Indices in 18 Chinese teaproducing provinces

As for the provincial disparties, Table 1 and Figure 2 revealed that Guangdong province had the highest TFP due to the highest technical efficiency change and pure technical efficiency change. However, Chongqing had the highest technological change and Guangdong was the second highest. It illustrated that there were great growth potentical in technical progress. Hainan had the highest scale efficiency change, which showing that Hainan was increasing its tea planting areas. Generally, there were great disparties in TFP Malmquist index among the 18 tea-producing provinces. Overall the majority of provinces had the effective total factor efficiency except Jiangsu province. All provinces had the effective technology progress which was more than 1 , which meant that technical efficiency was improved and technology was progressing. 8 provinces had the effective technical efficiency, 13 provinces had the effective pure technical efficiency and 7 provinces had the effective scale efficiency. We can conclude that TFP change synchronized with technological change, technical efficiency change and pure technical efficiency change, but was inversely proportional to the scale efficiency change. Moreover, the inefficiency of the tea industry was caused by scale inefficiency. As a result, the emphasis of improving technical efficiency of the tea industry was to improve scale efficiecy.

\section{Conclusions and recommendations}

Based on the technical efficiency theory, this paper discussed the mode of the tea industry development. Taking the panel data from 2014 to 2019 of China's tea industry, we use the DEA Malmquist method to calculate the tea industry total factor productivity index, technical level index, scale efficiency and technical efficiency change index of tea industry. Based on the above research results, the paper drew the following conclusions:

First, from 2014 to 2019, the total factor productivity showed a fluctuate rise. Overall TFP of China's tea industry increased by $12.8 \%$ on average; and technical efficiency increased by $9.7 \%$ on average and technology progress level increased by $14.9 \%$ on average.

Second, from 2014 to 2019, the average technical efficiency of the tea industry was smaller, but basically showed a trend of rising. The technical efficiency of tea industry showed a sustainable rise, but still in a state of inefficiency caused by scale inefficiency.

Third, there were great gaps among the main 18 teaproducing provinces in China. Guangdong had the 
highest total factor productivity Malmquist index. Chongqing had the highest technological change and Hainan had the highest scale efficiency change. In general, TFP Malmquist change index synchronized with technical efficiency change and pure technical efficiency change, but it was inverse to scale efficiency.

Based on the above conclusions, this paper put forward the following policy recommendations:

First, the government should deepen the technical innovation and progress. Technical progress was the main impetus for recent quick development of China tea industry. It promoted tea industry transition from extensive form to intensive form, which meant that the improvement of total factor productivity no longer relied on scale expand but on the technical innovation and progress. Hence, technology content of tea products should be increased and studies on intensive cultivation techniques should be developed and promoted to technical progress and innovation in tea marketing and brand construction.

Second, we should plant tea in rational scale to improve scale efficiency. Under circumstance of supply exceeding demand on international tea market, optimization technology should be developed to promote connotative development in Chinese tea industry and to accelerate the transition from pursuing quantity to improving quality. Even though we want to adjust and optimize the production scale of tea industry, we should consider the characteristics of different areas and tea varieties instead of blindly carrying out scale adjustment.

Third, the production effectiveness of tea industry should be improved and labour input and indirect costs should be reduced to reduce resource waste during tea production. Meanwhile, pure technical efficiency in tea production and processing should be improved to accelerate the system reform in different processing area and to increase motivating labour and rational use of production factors.

\section{Acknowledgement}

This research was financially supported by Fujian University of Technology Research Start-up Project under grant GY-S18100.

\section{References:}

[1] Van Ho, B., Nanseki, T. \& Chomei, Y. Profit efficiency of tea farmers: case study of safe and conventional farmers in Northern Vietnam,
Environmental development and sustainability. Vol.4, No.4, 2018, pp. 1-19.

[2] Hong, N.B. \& Yabe, M.. Profit efficiency of tea production in the Northern Mountainous Region of Vietnam, Journal of the International Society for Southeast Asian Agricultural Sciences, Vol.21, No.1, 2015, pp.1-17.

[3] S. Zhang, "Evaluating the Method of Total Factor Productivity Growth and Analysis of Its Influencing Factors During the Economic Transitional Period in China," J. Cleaner Production, vol. 107, 2015, pp. 438-44.

[4] K. Li and B. Lin. "Impact of Energy Conservation Policies on the Green Productivity in China's Manufacturing Sector: Evidence from a Three-Sage DEA Model," Applied Energy, vol. 168, 2016, pp. 351-63.

[5] D. Tang et al., "Environmental Regulation Efficiency and Total Factor Productivity-Effect Analysis Based on Chinese Data from 2003 to 2013," Ecological Indicators, vol. 73, 2017, pp. 312-18.

[6] Xianshu Zeng. Integrated emergy and economic evaluation of tea production chains in Anxi, China. Ecological Engineering. Vol.60, No.4, 2013, pp.354362

[7] Fexter Katungwe. Technical Efficiency of Smallholder Tea Production in South-Eastern Malawi: A Stochastic Frontier Approach. The Journal of Agricultural Sciences. Vol.12, No.3, 2017, pp.185-196

[8] Z. Ghaderi. Efficiency Analysis of Traditional Tea Farms in Iran. Economics of Agriculture, Vol.66,No.2, 2019, pp.423-436

[9] J. Zhang, X. Qu and A. K. Sangaiah, A Study of Green Development Mode and Total Factor Productivity of the Food Industry Based on the Industrial Internet of Things, IEEE Communications Magazine, Vol. 56, No. 5, 2018, pp. 72-78.

[10] Josiah M Ateka, Perez A. Onono \& Martin Etyang. Technical Efficiency and its Determinants in Smallholder Tea Production: Evidence from Nyamira and Bomet Counties in Kenya. Global Journal of Science Frontier Research. Vol.15, No.3, 2018, pp.42-54

[11] Nguyen-Van P, To The N. Technical efficiency and agricultural policy: evidence from the tea production in Vietnam. Rev Agric Food Environ Stud Vol.97, No.3 ,2016, pp.173-184

[12] Hong, N. B., Takahashi, Y., \& Yabe, M. Environmental efficiency and economic losses of Vietnamese tea production: Implications for cost savings and environmental protection. Journal of the Faculty of Agriculture, Kyushu University, Vol. 61 No.2, 2016, pp.383-390. 
[13]Nguyen To The. Efficiency and adoption of organic tea production: Evidence from Vi Xuyen district, Ha Giang province, Vietnam. Asia-Pacific Journal of Regional Science, Vol.10, No.7,2018, pp. $1-17$

[14] Nguyen Nhu Trang. Determinants of Linking Gaps Tea Production: Case Study of Tea Production Households in Northern Midland and Mountainous Region, Vietnam. Journal of Business Management and Economic Research, Vol.3, No.3,2019, pp.34-45 [15] Nguyen Bich Hong and Mitsuyasu Yabe. Profit efficiency of tea production in the northern mountainous region of Vietnam. Journal of The International Society for Southeast Asian Agricultural Sciences. Vol.21 No.1, 2015, pp.1-17

[16] Nguyen Bich Hong \& Mitsuyasu Yabe. Technical Efficiency Analysis of Tea Production in the Northern Mountainous Region of Vietnam. Global Journal of Science Frontier Research: Agriculture and Veterinary, Vol.15, No.1, 2015, pp. $30-42$

[17] Shamsheer ul Ha. Estimating the efficiency level of different tea farming systems in Rize Province Turkey. Ciência Rural, Santa Maria, Vol.49, No.12, 2019, pp.1-12

[18] Phu Nguyen-Van. Technical efficiency and agricultural policy: evidence from the tea production in Vietnam. Rev Agric Food Environ Study. Vol1.6, No.6, 2016, pp.1-12

[19] Maity, S. 'Farm size and economic efficiency: a case study of tea production in West Bengal', Int. J. Sustainable Economy, Vol. 4, No. 1, 2012.pp.53-70. [20] Liu, H. and Shao, S. India's Tea Price Analysis Based on ARMA Model. Modern Economy, Vol. 2, No.7, 2016, pp.118-123.

[21] Mohan Munasinghe. Economic, social and environmental impacts and overall sustainability of the tea sector in Sri Lanka. Sustainable Production and Consumption, Vol.12, No.3, 2017, pp.155-169

[22] Jauhar Samudera. Competitive of Indonesian Tea in International Market. Indonesian Journal of Business and Entrepreneurship, Vol.3, No.1 ,2017, pp.14-23

[23] Hamed Kouchaki-Penchah. Environmental Management of Tea Production Using Joint of Life Cycle Assessment and Data Envelopment Analysis Approaches. Environmental Progress \& Sustainable Energy, Vol.20, No.1, 2017, pp.1-7

[24] Bimesh Shrestha. A Supply Chain Approach to Study Efficiency and Sustainability in The Nepalese Tea Industry. Bachelor's Thesis of Turku University of Applied Sciences. 2014

[25] IBRAHIM MOIRO OMARI. Determinants of export performance of Kenya tea development agency managed factories in Kenya. A thesis for degree of Doctor of Philosophy in Business Administration of Jmo Kenyatta University of Agriculture and Technology, 2015

\section{Creative Commons Attribution License 4.0 (Attribution 4.0 International, CC BY 4.0)}

This article is published under the terms of the Creative Commons Attribution License 4.0 https://creativecommons.org/licenses/by/4.0/deed.en_US 